\title{
Postprandial energy expenditure in whole-food and processed-food meals: implications for daily energy expenditure
}

\author{
Sadie B. Barr and Jonathan C. Wright*
}

Department of Biology, Pomona College, Claremont, CA, USA

Abstract

Background: Empirical evidence has shown that rising obesity rates closely parallel the increased consumption of processed foods (PF) consumption in USA. Differences in postprandial thermogenic responses to a whole-food (WF) meal vs. a PF meal may be a key factor in explaining obesity trends, but currently there is limited research exploring this potential link.

Objective: The goal was to determine if a particular PF meal has a greater thermodynamic efficiency than a comparable WF meal, thereby conferring a greater net-energy intake.

Design: Subjective satiation scores and postprandial energy expenditure were measured for 5-6 h after isoenergetic meals were ingested. The meals were either 'whole' or 'processed' cheese sandwiches; multi-grain bread and cheddar cheese were deemed whole, while white bread and processed cheese product were considered processed. Meals were comparable in terms of protein (15-20\%), carbohydrate (40-50\%), and fat (33-39\%) composition. Subjects were healthy women $(n=12)$ and men $(n=5)$ studied in a crossover design. Results: There were no significant differences in satiety ratings after the two meals. Average energy expenditure for the WF meal ( $137 \pm 14.1 \mathrm{kcal}, 19.9 \%$ of meal energy) was significantly larger than for the PF meal $(73.1 \pm 10.2 \mathrm{kcal}, 10.7 \%$ of meal energy).

Conclusion: Ingestion of the particular PF meal tested in this study decreases postprandial energy expenditure by nearly $50 \%$ compared with the isoenergetic WF meal. This reduction in daily energy expenditure has potential implications for diets comprised heavily of PFs and their associations with obesity.

Keywords: diet; nutrition; DIT; food processing; energy; metabolism; obesity

Received: I5 March 20I0; Revised: I May 20I0; Accepted: 16 June 20 I0; Published: 2 July 2010

W ithin the last 30 years the obesity rate for adult Americans has more than doubled from 15 to $32 \%$ and currently it is estimated that twothirds of Americans are either overweight or obese, a 42\% increase since 1980 (1). A primary cause of this obesity epidemic is thought to be gross caloric intake $(2,3)$, which has risen by an estimated 300 calories per day in the past 25 years in the USA (4). This has a strong association with increased consumption of pre-prepared processed foods $(\mathrm{PF})(2,5,6)$ and insufficient consumption of whole foods (WF), such as fruits, vegetables, and whole grains (7). These trends call for more research into the physiological consequences of PF consumption and its possible relationship to net-energy balance.

Metabolic energy expenditure can be broken down into three processes: basal metabolic rate (BMR), diet-induced thermogenesis (DIT), and active metabolic rate (AMR)
(8). BMR is the energy cost associated with keeping the body functioning at rest and AMR is the energy expenditure resulting from daily physical activities (8). DIT - also referred to as the thermal effect of foods (TEF) or specific dynamic action (SDA) - is the body's increase in metabolism following the ingestion of food. It accounts for the energetic costs of postprandial processes such as food breakdown, enzyme synthesis, peristalsis, nutrient uptake/assimilation, and secondary metabolism (e.g. urea synthesis) and is typically responsible for about $10 \%$ of daily energy expenditure in humans (9).

DIT varies depending on the macronutrient content of the food ingested. Metabolism of carbohydrates is more energetically expensive than that of fats, and protein metabolism is the most energy-demanding of all (10-12). In general, DIT will be higher, and net assimilated energy lower, when a meal comprises more complex substrates 
requiring greater enzyme synthesis and more extensive secondary metabolism in the liver $(8,13,14)$. When compared to whole foods, PFs characteristically have a lower nutrient density (i.e. a lower content and diversity of nutrients per calorie), less dietary fiber, and an excess of simple carbohydrates (15-17), which makes them structurally and chemically simpler than whole foods and predictably easier to digest $(15,16,18)$.

Surprisingly, very little research has evaluated the effects of food processing on digestion. Most DIT studies involving humans have focused on DIT energy expenditure for meals of differing macronutrient content (10-12). To our knowledge, none has measured DIT in response to complete meals that are similar in macronutrient composition but differ in the degree of processing.

It is hypothesized here that more extensively processed foods have a greater thermodynamic efficiency (and thus a greater metabolic disadvantage) than less processed or whole foods. The present study tests this by comparing the DIT responses of two isoenergetic meals.

\section{Methods}

The study protocol was approved by the Institutional Review Board of Pomona College. All participants were at least 18 years of age and provided written informed consent.

\section{Participants and recruitment}

Eight to fifteen subjects are needed to obtain statistically significant differences in mean postprandial data when using a crossover design (19). Thus, 18 eligible subjects (12 females, six males) were recruited for the study. Fifteen subjects were college students (aged 18-22 years) and three were adults aged 47-56 years. Subjects with severe dietary allergies, eating disorders, or regular use of medications (with the exception of birth control), or other serious health issues were excluded from participating. One subject (male, 20-year old) was excluded from final analyses because he contracted an illness during the time of the study. The subjects self-reported their body mass $(\mathrm{kg})$ and height $(\mathrm{m})$ for the BMI calculation (Table 1). Fourteen subjects had a BMI within the normal range of 18.5-25. One female was slightly below at 17.7 , one female was slightly above at 25.8 , and one male was slightly above at 26.3. These subjects were included in analyses because slight deviations outside the normal BMI range commonly occur (20).

\section{Meals}

The subjects completed two trials where they ingested two meal types, differing in degree of processing. Both meals consisted of bread and cheese sandwiches. The wholefood meal (WF) was comprised of multi-grain bread (which contained whole sunflower seeds and whole-grain kernels) and cheddar cheese, while the PF meal was comprised of white bread and a processed cheese product (Table 2, see Appendices A and B for ingredients and nutritional information). Paired WF and PF meals were isoenergetic and consisted of $600 \mathrm{kcal}$ portions $(2,520 \mathrm{~kJ}$, $1 \frac{1}{2}$ sandwiches $)$ or $800 \mathrm{kcal}$ portions $(3,360 \mathrm{~kJ}$, 2 sandwiches). Each subject was asked to choose a preferred portion size and consumed this portion size for each meal. Energy contents were derived from the food labels. These list the estimated available (not gross) calories using the nutrient information and assimilation coefficients for different foods compiled in the USDA 1973 report by Merrill and Watt (21). Seven females elected to eat the $600 \mathrm{kcal}$ portion, while the five males and the remaining five females elected to eat the $800 \mathrm{kcal}$ portion. Independent of portion size, each meal derived the same proportion of energy from both the bread and cheese (60\% bread, $40 \%$ cheese). WF meal composition was $40 \%$ carbohydrate, $39 \%$ fat, and $20 \%$ protein; $\mathrm{PF}$ meal composition was $50 \%$ carbohydrate, $33 \%$ fat, and $15 \%$ protein (Table 2 ). The WF meal had approximately three times the amount of dietary fiber than the PF meal.

Table 1. Characteristics of all study participants included in the final data analysis $(n=17)$

\begin{tabular}{|c|c|c|c|}
\hline Characteristic $^{\mathrm{a}}$ & $\begin{array}{c}\text { Women } \\
(n=12) \\
\text { Mean }\left(\mathrm{SE}^{\mathrm{b}}\right)\end{array}$ & $\begin{array}{c}\text { Men } \\
(n=5) \\
\text { Mean (SE) }\end{array}$ & $\begin{array}{l}\text { All subjects } \\
\quad(n=17) \\
\text { Mean (SE) }\end{array}$ \\
\hline Age (y) & 22.9 (2.9) & 32.6 (7.9) & $25.5(3.1)$ \\
\hline Mass (kg) & 60.1 (3.2) & 71.9 (4.7) & $63.6(2.8)$ \\
\hline Height (m) & I.68 (0.027) & $\mathrm{I} .77(0.024)$ & I.7I (0.024) \\
\hline $\mathrm{BMI}^{\mathrm{c}, \mathrm{d}}\left(\mathrm{kg} \mathrm{m}^{-2}\right)$ & $21.6(0.64)$ & $22.9(1.0)$ & $22.0(0.55)$ \\
\hline
\end{tabular}

\footnotetext{
${ }^{a}$ All characteristics self-reported by the subjects.

${ }^{\mathrm{b}} \mathrm{SE}=$ standard error of the mean.

${ }^{\mathrm{C}} \mathrm{BMI}=$ Body Mass Index, calculated from given age, mass, and height characteristics.

${ }^{d}$ BMI formula (19): BMI $\left(\mathrm{kg} \mathrm{m}^{-2}\right)=$ mass $(\mathrm{kg}) /[\text { height }(\mathrm{m})]^{2}$.
} 
Table 2. Energy composition of the two test meals for 800 and $600 \mathrm{kcal}$ portions

\begin{tabular}{|c|c|c|c|}
\hline \multicolumn{2}{|c|}{ Whole-food meal ${ }^{a}$} & \multicolumn{2}{|c|}{ Processed-food meal ${ }^{a}$} \\
\hline Serving: I $1 / 2$ sandwiches & Serving: 2 sandwiches & Serving: I $1 / 2$ sandwiches & Serving: 2 sandwiches \\
\hline kcal: $600(2,520 \mathrm{~kJ})^{\mathrm{b}}$ & kcal: 800 (3,360 kJ) & kcal: $600(2,520 \mathrm{~kJ})$ & kcal: 800 (3,360 kJ) \\
\hline Total fat: $26 \mathrm{~g}(39 \%)^{\mathrm{c}}$ & Total fat: $35 \mathrm{~g}(39 \%)$ & Total fat: 22 g (33\%) & Total fat: $29 \mathrm{~g}(33 \%)$ \\
\hline Sodium: I,050 mg & Sodium: I,400 mg & Sodium: I,646 mg & Sodium: 2,194 mg \\
\hline Total carbohydrate: $60 \mathrm{~g}(40 \%)$ & Total carbohydrate: $80 \mathrm{~g}(40 \%)$ & Total carbohydrate: 74 g (49\%) & Total carbohydrate: $99 \mathrm{~g}(50 \%)$ \\
\hline Dietary fiber: $9 \mathrm{~g}$ & Dietary fiber: $12 \mathrm{~g}$ & Dietary fiber: $<4.5 \mathrm{~g}$ & Dietary fiber: $<6 \mathrm{~g}$ \\
\hline Sugars: $12 \mathrm{~g}$ & Sugars: $16 \mathrm{~g}$ & Sugars: $12.4 \mathrm{~g}$ & Sugars: $16.5 \mathrm{~g}$ \\
\hline Protein: $30 \mathrm{~g}(20 \%)$ & Protein: 40 g (20\%) & Protein: 23 g (15\%) & Protein: $30 \mathrm{~g}(15 \%)$ \\
\hline Total dry weight ${ }^{\mathrm{d}}: 116 \mathrm{~g}$ & Total dry weight: $154 \mathrm{~g}$ & Total dry weight: $119 \mathrm{~g}$ & Total dry weight: $158 \mathrm{~g}$ \\
\hline
\end{tabular}

${ }^{\mathrm{a}}$ Information obtained from nutrition labels on food packages (see Appendices A and B).

b $\mathrm{kcal}=4.2 \mathrm{~kJ}$.

${ }^{c}$ Percentages $=$ the percentage of meal energy derived from that macronutrient. Percentages may not equal 100 due to rounding. I g of carbohydrate $=$ $4 \mathrm{kcal}, \mathrm{I} \mathrm{g}$ of $\mathrm{fat}=9 \mathrm{kcal}, \mathrm{I} \mathrm{g}$ of protein $=4 \mathrm{kcal}$.

${ }^{\mathrm{d}}$ Total dry weight $=$ fat $(\mathrm{g})+$ carbohydrates $(\mathrm{g})+$ protein $(\mathrm{g})$.

\section{Experimental protocol}

Each subject participated in two trials that were either performed on consecutive days or no longer than a week apart. The average duration of DIT for humans ranges from 3 to $6 \mathrm{~h}(8)$; thus there is no carry-over expected for subjects who participated on consecutive days. The basic protocol was identical for both days. Subjects were instructed to fast for $12 \mathrm{~h}$ prior to the beginning of the trial, and not to participate in any strenuous exercise during the day of the trial. Two BMR measurements were taken on the morning of the trial day, approximately $30 \mathrm{~min}$ before and immediately prior to eating the prescribed meal. The order in which the prescribed meals were eaten (i.e. WF or PF for the first trial) was randomly chosen for each subject. Subjects ingested the prescribed meal within a 20 -min period and were asked to return for six metabolic rate measurements at hourly intervals. Some subjects only required five measurements because their metabolic rate had returned to BMR by the fourth measurement. All meals were ingested between 9:15 and 11:15 am and each subject ingested their meals at approximately the same time on each test day $( \pm 30 \mathrm{~min})$. During each measurement, oxygen consumption was recorded $\left(\mathrm{VO}_{2}, \mathrm{~L} \mathrm{~min}^{-1}\right)$ and subjects were asked to record their satiety on a scale of $1-10$. After the trial was complete, subjects were asked to rate the palatability of the meal and their perceived energy level on a scale of $1-10$.

\section{$\mathrm{VO}_{2}$ measurements and energy expenditure}

Before beginning each measurement, subjects were instructed to sit resting for approximately $2 \mathrm{~min}$ to ensure their breathing was not affected by physical activity. All measurements were taken while the subjects were sitting in a room maintained at $22^{\circ} \mathrm{C}$.
$\mathrm{VO}_{2}$ was measured by indirect calorimetry using an iWorx 2116 interface spirometer and Labscribe software (iWorx Inc., Durham, NC), and a Qubit Systems S102 Flow-Through Oxygen Sensor and Logger-Pro software (Qubit Systems, Kingston, Ontario, Canada). The spirometer was used to measure breath rate (BR, breaths $\min ^{-1}$ ) and average breath volume (BV, L). The oxygen analyzer was used to measure total oxygen uptake $\left(\partial \mathrm{O}_{2}\right)$.

Rate of $\mathrm{O}_{2}$ consumption:

$$
\mathrm{VO}_{2}\left(\mathrm{~L} \min ^{-1}\right)=\mathrm{BR} \times \mathrm{BV} \times \partial \mathrm{O}_{2}
$$

Total oxygen uptake: $\partial \mathrm{O}_{2}=\left[\mathrm{O}_{2}\right.$ ambient $]-\left[\mathrm{O}_{2}\right.$ exhaled $]$

At each measurement, subjects were asked to breathe into the spirometer for 2 min using a nose clip to direct total airflow through the spirometer. The last minute of breathing was used to measure breath frequency and mean breath volume. For measurements of $\partial_{2}$, subjects were asked to exhale 5-6 breaths into a gas bag, exhaling for $10 \mathrm{~s}$ for each breath, and following each one by two to three normal breaths. The contents of the gas bag were then drawn through the oxygen sensor by means of an air pump. Gas bags were vacuum extracted between measurements. The oxygen sensor was calibrated with pure nitrogen $(0 \%)$ and ambient lab air (20.95\%).

Metabolic rates for each hourly measurement period during the DIT response were calculated from the determined $\mathrm{VO}_{2}$ values using a modification of Wier's equation (22):

$$
\begin{aligned}
& \text { Metabolic rate }\left(\mathrm{kJ} \mathrm{min}^{-1}\right) \\
& =4.184[4.686+1.096(\mathrm{RQ}-0.707)] \mathrm{VO}_{2}
\end{aligned}
$$

The energy expenditure derived from this formula is established to have an error $<1 \%$ (22). RQ is the respiratory quotient, which was estimated for both meal 
types based on the macronutrient content of the meals and using published RQ values for carbohydrates: 1.0; proteins: 0.81 ; and fats: 0.70 (23). The calculated WF $\mathrm{RQ}=0.831$ and the calculated PF RQ $=0.844$.

\section{Data analyses}

BMR was determined by averaging the two pre-meal $\mathrm{VO}_{2}$ measurements. The DIT response was considered to be complete when $\mathrm{VO}_{2}$ returned to within one standard deviation of BMR. Thirteen subjects recorded $6 \mathrm{~h}$ of postprandial measurements, while four recorded for $5 \mathrm{~h}$. Duration of DIT (h), DIT metabolic scope $\left(\mathrm{VO}_{2} \max /\right.$ $\mathrm{BMR}$ ), and $T_{\mathrm{p}}$ (time to $\mathrm{VO}_{2}$ max, $\mathrm{h}$ ) were collected for all trials. Total DIT energy expenditure $(\mathrm{kJ})$ was determined by fitting a quartic equation to the DIT response curve, and calculating the area underneath the DIT response curve and above BMR. The DIT coefficient (\%) was calculated by dividing total DIT $(\mathrm{kJ})$ by the total energy content of the meal. Comparisons between WF and PF meals for all subjects combined were analyzed using pair-wise $t$-tests. The pair-wise differences between the WF and PF data were, in turn, compared between sexes and the two age-groups using a two-sample $t$-test. All statistical analyses were conducted using SPSS Version 16 (SPSS Inc, Chicago, IL) and were considered significant at $P<0.05$.

\section{Results}

Subjects rated the WF meal as more palatable than the PF meal $(P=0.005)$, but post-meal energy ratings did not differ (Table 3, $P=0.22$ ). Participants described their average daily diet as $72 \%$ whole foods and 28\% PFs. Satiety ratings are shown in Fig. 1. The satiety ratings showed no significant difference between the two meals when compared over the entire monitoring period $(P=$ $0.78)$ or when compared at any of the specific time periods $(P>0.10)$.

DIT response curves are graphed as the average increase above BMR to control for inter-individual variation in the subject's metabolic rates (Fig. 2) and metrics from these curves are summarized in Table 4 . The PF curve actually drops below BMR during the 6th hour

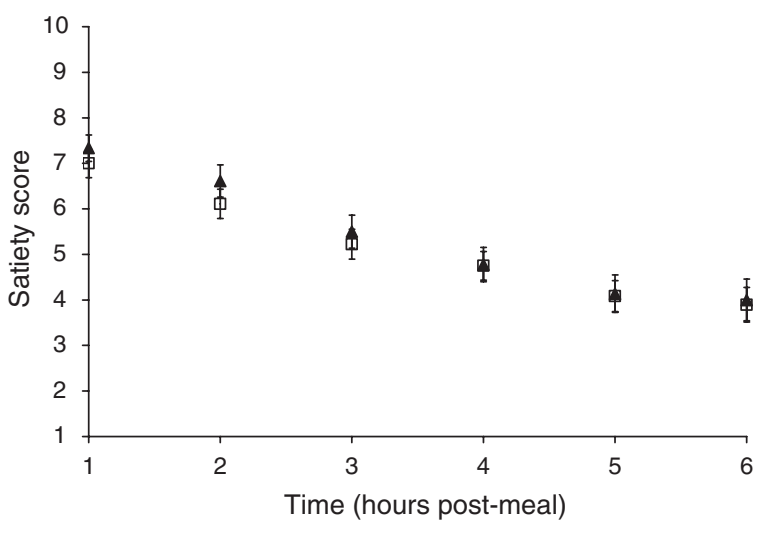

Fig. 1. Average subjective satiety scores $( \pm$ SE) for 17 healthy subjects over $6 \mathrm{~h}$ after whole food $(\square)$ and processed food $(\Delta)$ meal ingestion. Satiety scores did not differ significantly between the two trials $(P>0.1)$.

post-meal, while the WF curve never falls below BMR. Although the $T_{\mathrm{p}}$ and DIT metabolic scope did not differ significantly between $\mathrm{WF}$ and $\mathrm{PF}$ trials $(P=0.73$, $P=0.053)$, the total DIT $(\mathrm{kJ})$ and DIT coefficient $(\%)$ were significantly greater with the WF trials $(P=0.0009$, $P=0.005)$. The duration of the DIT curve for WF was also significantly greater, lasting on average a full hour longer than that of the PF curve $(P=0.001)$.

Analysis of total DIT and the DIT coefficient show clear differences between WF and PF. On average, WF DIT was nearly double PF DIT (Table 4). Taking into account different serving size portions for different subjects, the corresponding mean DIT coefficients are $19.9 \%( \pm 2.5 \%)$ for $\mathrm{WF}$, and $10.7 \%( \pm 1.7 \%)$ for $\mathrm{PF}$ (Table 4). Thus, the metabolic processes associated with DIT consumed approximately twice as much energy for the WF meal compared to the PF meal.

A difference between the sexes was apparent only for DIT metabolic scope which showed a larger mean difference between $\mathrm{WF}$ and $\mathrm{PF}$ in females than males (0.156 vs. $0.062 ; P=0.047)$. Comparisons of the various DIT parameters between the two age groups (data not shown), and for both the WF and PF meals, showed no significant differences with the exception of duration

Table 3. Subjective evaluations of the test meal palatability and energy rating post trials $(n=17)$

\begin{tabular}{lccc}
\hline Variable & Whole-food meal mean $\pm \mathrm{SE}^{\mathrm{a}}$ & Processed-food meal mean $\pm \mathrm{SE}$ & $P$-value \\
\hline Palatability rating $^{\mathrm{b}}$ & $6.5(0.32)$ & $4.9(0.43)$ & $0.005^{\mathrm{d}}$ \\
Energy rating $^{\mathrm{c}}$ & $5.3(0.47)$ & $4.6(0.36)$ & $0.22(\mathrm{NS})^{\mathrm{e}}$ \\
\hline
\end{tabular}

\footnotetext{
${ }^{\mathrm{a}} \mathrm{SE}=$ standard error.

${ }^{b}$ Palatability of each meal was rated by the subject on a scale of $\mathrm{I}-10$ after the completion of the trial, $\mathrm{I}=$ least palatable, $10=$ most palatable. ${ }^{\mathrm{c}} P<0.01$.

${ }^{\mathrm{d}}$ Subjects rated their own perceived energy level at the completion of each trial, I =least amount of energy, $10=$ most amount of energy. NS, not significant, $P>0.05$.
} 


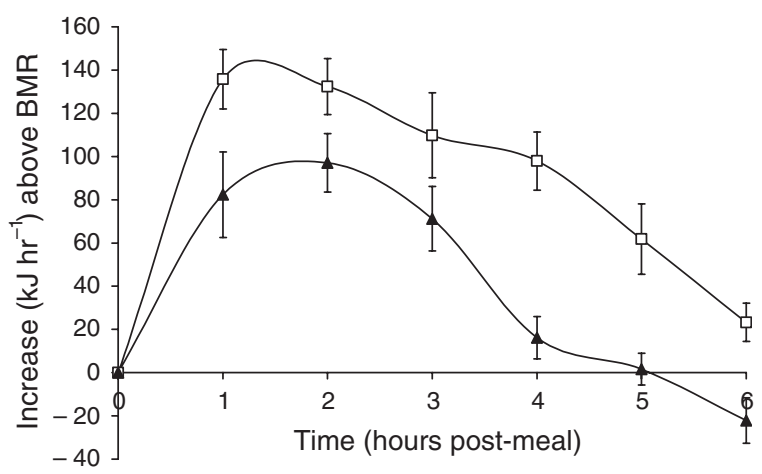

Fig. 2. Average increase in metabolic rate $( \pm \mathrm{SE})$ above basal metabolic rate for $6 \mathrm{~h}$ after whole $(\square)$ and processed ( $\Delta$ ) meal trials for 17 healthy individuals.

which showed a sparingly significant difference for the WF meal only $(6.0 \mathrm{~h}$ for the older age group [ $n=3]$, $5.71 \mathrm{~h}$ for the younger $[n=14] ; P=0.040)$.

\section{Discussion}

The results of this study suggest that this PF meal is more thermodynamically efficient than the comparable WF meal, and thus confers a metabolic disadvantage in relation to obesity. The DIT of the PF meal was $46.8 \%$ lower than the DIT of the WF meal. When the calculated DIT values for the two meals (i.e. expended meal calories) are subtracted from the total meal energy in each case, the difference in DIT results in a $9.7 \%$ increase in net energy-gain for the PF meal.

\section{Macronutrient composition}

The meals selected for this study were standardized for overall energy content, which resulted in a small discrepancy in the macronutrient composition. Protein is generally accepted to require the greatest energy expenditure in DIT $(20-30 \%)$, followed by carbohydrates $(5-10 \%)$, and fats $(0-3 \%)(9)$. Taking this into account, the significant findings of this study could be influenced by the $5 \%$ greater protein content of the WF meal (Table 2). However, the difference in protein content is much smaller than the observed difference in DIT and will be partly offset by the lower carbohydrate/fat ratio of the WF meal. Further, other studies have tended to show a relatively small effect of protein content on overall DIT $(12,14)$. Most processed meals in the typical American diet are higher in carbohydrates and lower in protein than comparable WF meals (17). Consequently, even if reduced protein content is only a minor contributor to differences in DIT, it will tend to exacerbate, rather than offset, the metabolic disadvantage of PFs.

\section{Palatability}

LeBlanc and Brondel (24) suggested that a highly palatable meal elicits a greater DIT response than a tasteless, unpalatable meal consisting of the same ingredients. However, subsequent studies have found that DIT does not vary with palatability or meal sweetness $(25,26)$. Although subjects in the present study rated the WF meal as more palatable, we think it is unlikely that this has a significant effect on the DIT differences, particularly since the ratings for both meals were not very disparate (Table 3 ), and the PF meal was not 'tasteless' as in the aforementioned study (24).

\section{Food composition and nutrient quality}

Quality differences between WFs and PFs help to explain why more energy would be needed in the digestion of WF. Most PFs contain refined grains (17); the milling used to produce refined grains removes most of the bran and germ, and the accompanying nutrients that they offer, such as B vitamins, phytonutrients, phenols, minerals,

Table 4. Diet induced thermogenesis (DIT) parameters for both whole and processed food trials $(n=17)$

\begin{tabular}{lccc}
\hline DIT parameter & Whole-food meal mean $\pm \mathrm{SE}^{\mathrm{b}}$ & Processed-food meal mean \pm SE & $P$-value \\
\hline $\mathrm{TP}^{\mathrm{c}}$ (hours) & $1.9(0.28)$ & $1.8(0.18)$ & 0.73 \\
Scope $^{\mathrm{d}}$ (ratio) & $1.4(0.04)$ & $1.3(0.03)$ & 0.053 \\
Duration $^{\mathrm{e}}$ (hours) & $5.8(0.1 \mathrm{l})$ & $4.8(0.23)$ & $0.00 \mathrm{I}^{\mathrm{f}}$ \\
Total DIT $^{\mathrm{g}}(\mathrm{kJ})$ & $576.3(59)$ & $306.9(42.6)$ & $0.0009^{\mathrm{h}}$ \\
DIT coefficient $(\%)$ & $19.9(2.5)$ & $10.7(1.7)$ & $0.005^{\mathrm{f}}$ \\
\hline
\end{tabular}

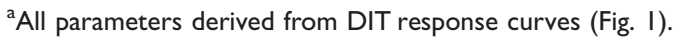

${ }^{\mathrm{b}} \mathrm{SE}=$ standard error.

${ }^{\mathrm{c}} \mathrm{T}_{\mathrm{P}}=$ time to peak $=$ hours needed to reach $\mathrm{VO}_{2}$ max .

${ }^{\mathrm{d}} \mathrm{Scope}=\mathrm{VO}_{2} \max \mathrm{BMR}^{-1}$.

${ }^{\mathrm{e}}$ Duration $=$ time needed for $M R$ to return within one standard deviation of BMR.

${ }^{f} \mathrm{P}<0.01$.

${ }^{\mathrm{g}}$ Total DIT $=$ total amount of energy expended during DIT response.

${ }^{\mathrm{h}} \mathrm{P}<0.001$.

'DIT coefficient $=$ percentage of meal energy burned during DIT response $=[$ Total DIT $(\mathrm{kJ}) /$ meal $(\mathrm{kJ})] \times 100$.
} 
fiber, and proteins. The removal of germ contributes to the lower protein content of refined grains and the removal of fiber-rich bran makes the remaining starch more readily digestible (18).

The mechanized preparation of PFs may also cause the loss of many potentially health-promoting components such as bioactives (i.e. isoflavones and antioxidants), phytochemicals, amino acids, and fiber (15-17). This is partially due to the removal of the bran fraction in wheat milling, which is associated with reductions in diverse phenolics, total antioxidant capacity, and $\beta$-carotene (15, 27). Consequently, PFs tend to have fewer metabolites, and thus require less enzyme production and peristalsis, simpler absorption, and less secondary metabolism, all of which demand energy expenditure $(8,28)$. Further, PFs have been shown to have a higher glycemic index than non-processed counterparts $(18,29,30)$, and the loss of fiber tends to decrease meal bulk and slow satiation both of which result in increased daily caloric intake (29-31).

\section{The role of fiber}

The WF meal tested in this study has approximately three times the amount of fiber as the PF meal (Table 2, see Appendices A and B for nutrition details) and although the exact relationship of meal fiber content and DIT is poorly known $(31,32)$, high-fiber diets are known to decrease the assimilation efficiency of foods (33). According to FDA and USDA guidelines, the calories on food labels list only assimilated calories, so this does not introduce a known discrepancy into our calculated isocaloric meal sizes (21). However, assimilated products from fermentable fiber tend to make accurate assessments of overall caloric assimilation difficult (32). This should be a minor problem for the present study given that the primary fiber source, wheat bran, is mainly insoluble and subject to less breakdown than more fermentable fibers (i.e. those found in fruit) (34). Bran-fiber does contribute to some short-chain fatty acid absorption by the colon, but to a small degree that would not significantly impact our results $(34,35)$.

\section{Study limitations}

It is important to recognize that the WFs and PFs used in this study represent different degrees of food refinement. A more strict WF would be one devoid of any processing, such as a specific fruit, vegetable, or meat. However, for the present study, we sought to compare two meals that were familiar to the Western diet, and could be easily interchangeable.

Because the results of this study are based on only a single meal comparison, appropriate caution must be applied when extrapolating the findings to other meals or to the Western diet in general. However, if future studies indicate that reduced DIT is a common characteristic of
PFs, this suggests a simple means by which to alter dietary habits to counter weight gain.

\section{Conclusions}

A higher thermogenic response was observed after a meal composed of whole foods than after an equivalent and isocaloric meal comprised of highly PFs. The lower DIT of the PF meal indicates greater net-energy assimilation. These findings are currently relevant only to this type of meal, and future studies are required to determine whether a reduction in DIT is characteristic of PFs generally. Such a pattern is, however, predicted on thermodynamic grounds. If the findings of the present study are supported by future work, this would indicate that diets with a high proportion of PFs will result in increased energy assimilation and may be a contributor to weight gain.

\section{Acknowledgements}

The authors gratefully acknowledge the assistance of the Department of Biology, Pomona College, and the study participants.

\section{Conflict of interest}

This study was funded by funds from the Howard Hughes Medical Institute and Pomona College.

\section{References}

1. US Centers for Disease Control and Prevention. National Center for Health Statistics. Health, United States. Atlanta, GA: US Department of Health and Human Services; 2003.

2. World Health Organization (WHO). Diet, nutrition and the prevention of chronic diseases. Report of a joint WHO/FAO Expert Consultation. WHO Technical Report Series No. 916. Geneva; 2003.

3. Anand RS, Basiotis P, Kennedy E. Rise in amount of total fat and number of calories consumed by Americans. Fed Am Soc Exp Biol J 1997; 11: A183. (Abstract)

4. Robert Wood Johnson Foundation and Trust for America's Health. $\mathrm{F}$ as in fat, How obesity policies are failing in America. Princeton, NJ/Washington, DC; 2009.

5. Cutler DM, Glaeser EL, Shapiro JM. Why have Americans become more obese? J Econ Perspectives 2003; 17: 93-118.

6. Graaf C. de. Effects of snacks on energy intake: an evolutionary perspective. Appetite 2007; 47: 18-23.

7. Ogden CL, Carrol MD, Curtin LR, Mcdowell MA, Tabak CJ, Flegal KM. Prevalence of overweight and obesity in the United States, 1999-2004. JAMA 2006; 295: 1549-55.

8. Secor SM. Specific dynamic action: a review of the postprandial metabolic response. J Comp Physiol B 2009; 179: 1-56.

9. Westerterp KR. Diet induced thermogenesis. Nutr Metab 2004; 1: 5 .

10. Raben A, Agerholm-Larsen L, Flint A, Holst JJ, Astrup A. Meals with similar energy densitites but rich in protein, fat, carbohydrate, or alcohol have different effects on energy expenditure and substrate metabolism but not on appetite and energy intake. Am J Clin Nutr 2003; 77: 91-100. 
11. Dauncey MJ, Bingham SA. Dependence of $24 \mathrm{~h}$ energy expenditure in man on the composition of the nutrient intake. Brit J Nutr 1983; 50: 1-13.

12. Whitehead JM, McNeill G, Smith JS. The effect of protein intake on 24-h energy expenditure during energy restriction. Int J Obes Relat Metab Disord 1996; 20: 727-32.

13. Wyle-Rosett J, Segal-Isaacson CJ, Segal-Isaacson A. Carbohydrates and increases in obesity: does the type of carbohydrate make a difference? Obesity Res 2004; 12: 124S-9S.

14. de Jonge L, Bray GA. The thermic effect of food and obesity: a critical review. Obes Res 1997; 5: 622-31.

15. Shahidi F. Nutraceuticals and functional foods: whole versus processed foods. Trends Food Sci Technol 2009; 20: 376-87.

16. Monteiro CA. Nutrition and health. The issue is not food, nor nutrients, so much as processing. Public Health Nutr 2009; 12: 729-31.

17. Cordain L, Eaton SB, Sebastian A, Mann N, Lindeberg S, Watkins BA, et al. Origins and evolution of the Western diet: health implications for the 21st century. Am J Clin Nutr 2005; 81: $341-54$.

18. Brand JC, Nicholson PL, Thorburn AW, Truswell AS. Food processing and the glycemic index. Am J Clin Nutr 1985; 42: $1192-6$.

19. Flint A, Raben A, Blundell JE, Astrup A. Reproducibility, power and validity of visual analogue scales in assessment of appetite sensations in single meal test studies. Int $\mathrm{J}$ Obes Relat Metab Disord 2000; 24: 38-48.

20. US Centers for Disease Control and Prevention. "About BMI for adults," division of nutrition, physical activity, and obesity. Available from: http://www.cdc.gov/healthyweight/assessing/bmi/ adult_bmi/index.html [cited 15 May 2009].

21. Merrill AL, Watt BK. Energy value of foods - basis and derivation. Agriculture Handbook No. 74. Agricultural Research Service, United States Department of Agriculture; 1973.

22. Weststrate JA. Resting metabolic rate and diet-induced thermogenesis: a methodological reappraisal. Am J Clin Nutr 1993; 58: 592-601.

23. Lusk G. The elements of the science of nutrition, 4th ed. Philadelphia, PA: Saunders; 1931.

24. LeBlanc J, Brondel L. Role of palatability on meal-induced thermogenesis in human subjects. Am J Physiol 1985; 248: E333-6.
25. Weststrate JA, Dopheide T, Robroch L, Deurenberg P, Hautvast JGAJ. Does variation in palatability affect the postprandial response in energy expenditure? Appetite 1990; 15: 209-19.

26. Prat-Larquemin L, Oppert J-M, Bellisle F, Guy-Grand B. Sweet taste of aspartame and sucrose: effects on diet-induced thermogenesis. Appetite 2000; 34: 245-51.

27. Liyana-Pathirana CM, Dexter J, Shahidi F. Antioxidant properties of wheat as affected by pearling. J Agric Food Chem 2006; 54: 6177-84.

28. Eaton SB. Opening lecture: the ancestral human diet: what was it and should it be a paradigm for contemporary nutrition? Proc Nutr Soc 2006; 65: 1-6.

29. Ludwig DS, Majzoub JA, Al-Zahrani A, Dallal GE, Blanco I, Roberts SB. High glycemic index foods, overeating, and obesity. Pediatrics 1999; 103: E26.

30. Roberts SB. High-glycemic index foods, hunger and obesity: is there a connection? Nut Rev 2000; 58: 163-70.

31. Raben A, Christensen NJ, Madsen J, Holst JJ, Astrup A. Decreased postprandial thermogenesis and fat oxidation but increased fullness after a high-fiber meal compared with a lowfiber meal. Am J Clin Nutr 1994; 59: 1386-94.

32. Salzman E, Roberts SB. Soluble fiber and energy regulation current knowledge and future directions. In: Dietary fiber in health and disease (Adv Exp Med and Biology 427). New York: Plenum Press; 1997. pp. 89-97.

33. Miles CW. The metabolizable energy of diets differing in dietary fat and fiber measured in humans. J Nutr 1991; 122: 306-11.

34. Topping DL, Clifton PM. Short-chain fatty acids and human colonic function: roles of resistance starch and nonstarch polysaccharides. Physiol Rev 2001; 81: 1031-64.

35. Smith T, Brown JC, Livesey G. Energy balance and thermogenesis in rats consuming non-starch polysaccharides of various fermentabilites. Am J Clin Nutr 1998; 68: 802-19.

\footnotetext{
*Jonathan C. Wright

Department of Biology

Pomona College

75 West 6th Street

Claremont, CA 9|7।I, USA

Email: jcwright@pomona.edu
} 


\section{APPENDIX}

Appendix A. Cheese nutrition facts and ingredients.

Whole

Processed

Sargento Natural Medium Cheddar (Deli style sliced Cheddar Cheese) Serving size: I slice ( 2 I g)

Servings per container: II

Calories: 80

Calories from fat: 70

Total fat: $7 \mathrm{~g}$

Sat fat: $4 \mathrm{~g}$

Trans fat: $0 \mathrm{~g}$

Cholesterol: $20 \mathrm{mg}$

Sodium: $140 \mathrm{mg}$

Total carbohydrates: $0 \mathrm{~g}$

Dietary fiber: $0 \mathrm{~g}$

Sugars: $0 \mathrm{~g}$

Protein: $5 \mathrm{~g}$

Calcium: $15 \%^{*}$

Vit A: $6 \%$

Vit C: $0 \%$

Iron: $0 \%$

Vit D: $0 \%$

Ingredients: pasteurized milk, cheese culture, salt, enzymes, annatto (vegetable color), Natamycin (A natural mold inhibitor).
Kraft Singles American, Pasteurized prepared cheese product.

Serving size: I slice (2। g)

Servings per container: 8

Calories: 70

Calories from fat: 45

Total fat: $5 \mathrm{~g}$

Sat. fat: $3 \mathrm{~g}$

Trans fat: $0 \mathrm{~g}$

Cholesterol: $20 \mathrm{mg}$

Sodium: $270 \mathrm{mg}$

Total carbohydrates: $2 \mathrm{~g}$

Dietary fiber: $0 \mathrm{~g}$

Sugars: I g

Protein: $4 \mathrm{~g}$

Calcium: $25 \%$

Vit A: $4 \%$

Vit C: $0 \%$

Iron: $0 \%$

Vit D: $0 \%$

Ingredients: milk, whey, milkfat, milk protein concentrate, salt, calcium phosphate, sodium citrate, whey protein concentrate, sodium phosphate, sorbic acid as a preservative, apocarotenal (color), annatto (color), enzymes, vitamin D3, cheese culture.

*Percent of daily recommended intake. 
Appendix B. Bread nutrition facts and ingredients.

\begin{tabular}{|c|c|}
\hline Whole food & Processed food \\
\hline $\begin{array}{l}\text { Sara Lee Hearty \& Delicious 100\% Multi-Grain (Heart healthy, } \\
\qquad \text { 100\% Natural); }\end{array}$ & Weber's Enriched Bread \\
\hline Serving size: I slice (43 g) & Serving size: I slice (3 I g) \\
\hline Servings per container: 16 & Servings per container: 22 \\
\hline Calories: 120 & Calories: 80 \\
\hline Calories from fat: 15 & Calories from fat: 10 \\
\hline Total fat: $1.5 \mathrm{~g}$ & Total fat: I g \\
\hline Sat fat: $0.5 \mathrm{~g}$ & Sat fat: $0 \mathrm{~g}$ \\
\hline Trans fat: $0 \mathrm{~g}$ & Trans fat: $0 \mathrm{~g}$ \\
\hline \multicolumn{2}{|l|}{ Polyunsaturated fat: I g } \\
\hline \multicolumn{2}{|l|}{ Monounsaturated fat: $0 \mathrm{~g}$} \\
\hline Cholesterol: $0 \mathrm{mg}$ & Cholesterol: $0 \mathrm{mg}$ \\
\hline Sodium: $210 \mathrm{mg}$ & Sodium: $160 \mathrm{mg}$ \\
\hline Total carbohydrates: $20 \mathrm{~g}$ & Total carbohydrates: $15 \mathrm{~g}$ \\
\hline Dietary fiber: $3 \mathrm{~g}$ & Dietary fiber: less than I g \\
\hline Sugars: $4 \mathrm{~g}$ & Sugars: $2 \mathrm{~g}$ \\
\hline Protein: $5 \mathrm{~g}$ & Protein: $2 \mathrm{~g}$ \\
\hline Vit A: $0 \%$ & Vit A: $0 \%$ \\
\hline Vit C: $0 \%$ & Vit C: $0 \%$ \\
\hline Calcium: $0 \%$ & Calcium: $4 \%$ \\
\hline Iron: $6 \%$ & Iron: $6 \%$ \\
\hline Thiamin: $8 \%$ & Thiamin: $10 \%$ \\
\hline Riboflavin: $4 \%$ & Riboflavin: $6 \%$ \\
\hline Niacin: $8 \%$ & Niacin: $6 \%$ \\
\hline Folic Acid: 6\% & Folic Acid: $8 \%$ \\
\hline $\begin{array}{l}\text { Ingredients: Stone-ground whole wheat flour, water, brown sugar, wheat } \\
\text { gluten, yeast, contains } 2 \% \text { or less of each of the following: vegetable oil } \\
\text { (soybean and or/cottonseed oils), whole wheat, sunflower seeds, rye, } \\
\text { cultured wheat flour, salt, raisin juice concentrate, oats, barley, corn, } \\
\text { millet, triticale, distilled vinegar, guar gum, enzymes, enzyme-modified } \\
\text { soy lecithin, wheat bran, soy flour. }\end{array}$ & $\begin{array}{l}\text { Ingredients: Unbleached enriched flour [wheat flour, malted barley flour, } \\
\text { reduced iron, niacin, thiamin mononitrate (vitamin BI), riboflavin (vitamin } \\
\text { B2), folic acid], water, high fructose corn syrup, yeast, soybean oil, salt, } \\
\text { wheat gluten, calcium propionate (preservative), monoglycerides, datem, } \\
\text { ascorbic acid (dough conditioner), soy lecithin. }\end{array}$ \\
\hline
\end{tabular}

